\title{
Farklı Sulama Programlarının Şekerpancarında Kaliteye Etkisi
}

\author{
*Ali Fuat TARI ${ }^{1} \quad$ Aynur ÖZBAHÇE ${ }^{2} \quad$ Gülseren ATA ${ }^{3} \quad$ Ceren BILLGiç ${ }^{4}$ \\ ${ }^{1}$ Harran Üniv., Ziraat Fakültesi, Tarımsal Yapılar ve Sulama Bölümü, Şanlıurfa \\ ${ }^{2}$ Toprak Gübre ve Su Kaynakları Merkez Araştırma Enstitüsü, Ankara \\ ${ }^{3}$ Tarım Reformu Genel Müdürlüğü, Ankara \\ ${ }^{4}$ Harran Üniv., Ziraat Fakültesi, Tarla Bitkileri Bölümü, Şanlıurfa \\ *Sorumlu yazar e-mail (Corresponding author e-mail): aftari@hotmail.com
}

\section{Öz}

Bu araştırma, Orta Anadolu koşullarında damla sulama yöntemi ile sulanan şekerpancarında farklı sulama gün aralığı ve farklı sulama düzeylerinin şeker pancarının kalitesi ve kalite parametreleri üzerine olan etkisini belirlemek amacıyla 2008-2009 yıllarında yürütülmüştür. Denemede damla sulama sistemi kullanılmış olup, sulama sistemi iki bitki sırası tek lateral hattından sulanacak şekilde düzenlenmiştir. Coyote çeşidinin (Beta vulgaris var. Coyote) kullanıldığı bu araştırma, Tesadüf Bloklarında Bölünmüş Parseller Deneme Deseni'nde ve 3 tekerrürlü olarak yürütülmüştür. Sulama suyu miktarının belirlenmesinde Class A Pan kabından oluşan açık su yüzeyi buharlaşmasından yararlanıımıştır. Denemede ana konuları sulama gün aralıkları (4-8-12 gün), alt konuları ise farklı sulama düzeyleri $(\mathrm{Kpc}=1.25, \mathrm{Kpc}=1.00, \mathrm{Kpc}=0.75$ ve $\mathrm{Kpc}=0.50)$ oluşturmuştur. Araştırma sonucunda, deneme konularının sulama suyu miktarları $279 \mathrm{~mm}$ ile $668 \mathrm{~mm}$ arasında, su tüketimi miktarları $520 \mathrm{~mm}$ ile $827 \mathrm{~mm}$ arasında, şeker oranları \%15.35 ile \%17.51 arasında, K miktarları 2.09 ile 2.84 arasında Na miktarları 0.71 ile 1.29 arasında ve $\alpha$ N miktarları 1.59 ile 2.76 arasında değişmiştir. Yapılan istatistiki değerlendirmeler sonucu uygulanan farklı sulama programlarının şekerpancarının kalitesi üzerine önemli etkilerinin $(p<0.01)$ olduğu belirlenmiştir.

Anahtar Kelimeler: Şeker pancarı, damla sulama, şeker oranı, sulama aralığı, class A pan

\section{Effects of Different Irrigation Interval and Irrigation Level on Quality of Sugar Beet}

\begin{abstract}
This study was carried out in order to determine different irrigation day intervals and irrigation levels on sugar beet quality parameters using drip irrigation under ecological conditions of Konya Plain in 2008 and 2009 years. The drip irrigation system is designed to irrigate two crop rows with one lateral line. Coyote cultivar (Beta vulgaris var. Coyote) was used in the randomized split block experimental design with three replications. Evaporation from Class A Pan has been used for determining the amount of irrigation water. The treatments were irrigation intervals (4-8-12 days) and the rates of the accumulated Class A Pan evaporation $\left(K_{1}=1.25\right.$, $\mathrm{K}_{2}=1.00, \mathrm{~K}_{3}=0.75$ and $\mathrm{K}_{4}=0.50$ ). According to our results, the amount of irrigation water in the treatments ranged from $279 \mathrm{~mm}$ to $668 \mathrm{~mm}$, water consumption amounts between $520 \mathrm{~mm}$ and $827 \mathrm{~mm}$ sugar content from $17.51 \%$ to $15.35 \%, \mathrm{~K}$ amounts between 2.09 and 2.84 with $\mathrm{Na}$ amount of $0.71 \mathrm{\alpha N}$ amounts between 1.29 and 1.59 to 2.76 . Our statistical evaluations indicated that different irrigation programs have a significant effect $(p<0.01)$ on the quality of sugar beet.
\end{abstract}

Keywords: Sugar beet, drip irrigation, sugar ratio, irrigation interval class A pan

\section{Giriş}

S: eker pancarı iklim koşuları bakımından geniş bir yelpazede yetiştirilebilen ve ứluluğa toleranslı bir bitkidir. (Tognetti ve ark. 2003; Sakellariou-Makrantonaki ve ark. 2002). $\mathrm{Bu}$ nedenle şeker pancarı Akdeniz ve Güneydoğu Anadolu Bölgesi hariç Türkiye'nin her bölgesinde yetiştirilmektedir. Konya Ovası
Orta Anadolu'da yer almakta olup Türkiye'nin en az yıllık yağış alan bölgesidir. Özellikle tarımsal üretimde sulu tarımın yaygınlaşması ovada su kaynaklarına olan talebi artırmıştır. Bu nedenle son yıllarda yer altı ve yer üstü su kaynaklarında kaygı verici bir azalma gözlenmektedir. Bölgede göller kurumaya yüz 
tutarken, yer altı su seviyesi hızla düşmektedir (Özbahçe ve Tarı, 2010).

Şeker pancarı, Konya Kapalı Havzasının önemli bir ticari alan ürünü olup havza Türkiye'nin en büyük üreticisi durumundadır. Söz konusu bölge 115.000 ha ekim alanı ile Türkiye'de şeker pancarı üretiminde $\% 35$ paya sahiptir (Topak ve ark. 2008). Şeker pancarı bölgede yaygın olarak yağmurlama ve yüzey sulama yöntemleri ile sulanmaktadır. Bu metotların teknik bakımdan uygun olarak uygulanmaması sulamaların etkinliğini azaltırken su kayıplarını artırmaktadır.

Bitkiler için gerekli sulama suyu gereksinimi ağırlıklı olarak yeraltı su kaynaklarından elde edilmekte, ancak Konya Kapalı Havzasının su kaynakları oldukça yetersizdir. Özellikle kurak bölgelerde şeker pancarı verimi, uygulanan sulama suyu miktarı ve yetişme döneminde düşen yağış miktarı ile yakından ilgilidir (Scott ve Jaggard, 1993). Buna bağlı olarak, sulama, tarımsal üretimde ve özellikle şeker pancarı yetiştiriciliğinde önemli bir rol oynar. Ülkemizin de içinde bulunduğu Akdeniz Havzası ikliminde ve arazi kullanımındaki değişiklikler tarımsal üretim için kullanılabilecek sulama suyu miktarını giderek daha sınılı hale getirecektir (Clarke, 1993). Gerçekten de, gelecekteki iklim senaryoları Akdeniz havzasında su kaynaklarının daha da azalabileceğini göstermektedir (Tognetti ve ark. 2003). Gelecek ile ilgili bu senaryo bizleri sulama suyunu olabilecek en yüksek randımanla kullanmaya ve kullanılan bir birim sudan en yüksek verimi elde etmeye zorunlu kılmaktadır (Ertek ve Kanber, 1999; Tekinel ve ark, 2000; Korukçu ve Büyükcangaz, 2003).

Yetersiz olan su kaynakları ile tüm sektörler bazında talebi karşılayabilmek için, en büyük su kullanıcı olan tarım sektöründe sulama randımanını artıran modern sulama teknolojileri kullanımı kaçınılmaz hale gelmiştir. Ayrıca, etkin bir su yönetimi uygulanmalıdır. Bitkiler için en uygun sulama programları oluşturulmalı ve bu program gereği uygulanacak sulama suyu en yüksek randıman ile bitkilere verilmelidir. Türkiye'de ise halen şekerpancarı yağmurlama sulama ya da yüzey sulama yöntemi ile

Çizelge 1. Deneme konuları

Table 1. Experiment Subjects

\begin{tabular}{cc}
\hline ANA KONULAR & ALT KONULAR \\
(Sulama gün aralığı) & (Sulama suyu düzeyleri) \\
\hline A- 4 günde sulama & $\mathrm{a}-(\mathrm{Kpc}=1.25)$ \\
B- 8 günde sulama & $\mathrm{b}-(\mathrm{Kpc}=1.00)$ \\
C- 12 günde sulama & $\mathrm{c}-(\mathrm{Kpc}=0.75)$ \\
& $\mathrm{d}-(\mathrm{Kpc}=0.50)$ \\
\hline
\end{tabular}

sulanmakta, sulamalarda ise genellikle topraktaki eksik nem veya bitkinin su gereksinimi göz önünde bulundurulmamaktadır. Bu nedenle yapılan sulamaların randımanları oldukça düşüktür (Tarı ve Yazar, 2010).

Yapılan araştırmalarda, Cassel Sharmasarkar ve ark. (2001) toprak üstü damla ve tava sulama metotlarının şeker pancarında su ve gübre kullanım etkinliği üzerine etkisini incelemişlerdir. Araştırmacılar damla sistemi ile tava sulamaya göre daha az su ve gübre kullanıldığı sonucuna varmışlardır. Kruse ve ark. (1990), ise uygun sulama uygulamaları ile ürün veriminin arttırabileceğini ifade etmişlerdir. Damla sulama, belirli koşullar altındaki bitki türlerinde yağmurlama veya karık sulama sistemlerine nazaran daha az sulama suyuna gereksinim duyar. Geleneksel sulama yöntemlerinin neden olduğu sorunlar nedeniyle yakın gelecekte tarla bitkilerinde damla sulama yönteminin kullanımı kaçınılmazdır. Damla sulama sık ve üniform sulamaya olanak vermesi, geniş bir topografik ve toprak koşullarında kullanılabilmesi nedeniyle birçok bitkinin sulanmasında önerilmektedir (Çetin and Bilgel, 2002).

$\mathrm{Bu}$ çalışma, son yıllarda sulanmasında damla sulama siteminin kullanılmaya başlandığı şeker pancarı bitkisinde kaliteyi artırmak için uygun sulama aralığı ve gerekli sulama suyu miktarını belirlemek amacı ile yürütülmüştür.

\section{Materyal ve Yöntem}

\section{Araştırma Yeri}

Deneme, Konya Kapalı Havzası içerisinde yer alan Konya Şeker A.Ş. Alakova deneme istasyonu arazisinde yürütülmüştür. Konya Kapalı Havzası'nın Yüzölçümü 5426980 hektar olup, Türkiye'nin \%7'sini teşkil etmektedir. Orta Anadolu Bölgesi'nde $36^{\circ} 51^{\prime}-$ $39^{\circ} 29^{\prime}$ kuzey enlemleri ile $31^{\circ} 36^{\prime}-34^{\circ} 52^{\prime}$ doğu boylamları arasında bulunmaktadır.

\section{Deneme Yerinin İklim, Toprak ve Su Özellikleri}

Ova toprakları genellikle ağır bünyelidir. Bazı kısımlarda orta bünyeli, pek az olarak da hafif bünyelidirler. Kireç bakımından zengin olup kireç 
oranı genellikle $\% 5$ 'ten fazladır. Ovanın denizden yüksekliği ortalama 1000 m'dir. Denemenin yürütüldüğü Konya Şeker A.Ş. Alakova deneme istasyonu arazisi toprakları; derin profilli, kil, killi tın bünyeli allüviyal topraklardır. Deneme yerinde taban suyu sorunu olmayıp, elverişli su tutma kapasitesi 160 mm/m'dir. Toprakların kireç içeriği yüksek, organik madde miktarı orta düzeyde olup, hafif alkali özellik göstermektedir. Denemede kullanılan sulama suyu deneme sahasında bulunan yer altı derin kuyusundan temin edilmiş olup $\mathrm{T}_{2} \mathrm{~A}_{1}$ sınıfındadır.

\section{Araştırma Yerinin İklim Özellikleri}

Konya'da hakim iklim, karasal iklimdir. Kış mevsimi sert ve soğuk, yazları sıcak ve kurak geçer. Yıllık ortalama sıcaklık $11.9^{\circ} \mathrm{C}$ 'dir. Uzun yıllar ortalama iklim verilerine göre; yıllık ortalama sıcaklık $11.9^{\circ} \mathrm{C}$, toplam yıllık yağış $323.6 \mathrm{~mm}$ olup, yağışlı dönem ekim ayında başlar, nisan ve mayıs ayları yağışın en fazla olduğu aylardır. Temmuz ve ağustos aylarında en düşük seviyede olan oransal nem, eylül ayından sonra yükselerek aralık ve ocak aylarında en yüksek seviyesine ulaşmaktadır. Türk Şeker Kurumunun Alakova Deneme İstasyonu rasat değerlerine göre bitki yetişme dönemi içerisinde ilk yıl 112.2 mm ikinci yıl ise $114.1 \mathrm{~mm}$ yağış düşmüştür.

Deneme tesadüf bloklarında bölünmüş parseller deneme deseninde 3 tekerrürlü olarak yürütülmüştür. Denemede ana konuları sulama aralıkları, alt konuları ise sulama düzeyleri oluşturmuştur. Buna göre oluşturulan deneme konuları Çizelge 1'de verilmiştir.

\section{Sulama Suyunun Hesaplanması}

Deneme konuları gereği uygulanacak sulama suyu miktarı, deneme alanında bulunan Class A Pan buharlaşma kabından oluşan buharlaşma miktarının farklı katsayıları ile çarpılarak belirlenmiştir. Söz konusu kaptan iki sulama zamanı arasında gerçekleşen buharlaşma miktarları pan katsayısı ve örtü yüzdesi ile çarpılarak sulama suyu miktarı belirlenmiştir. Sulama suyu miktarının hesaplanmasında aşağıdaki eşitlikten yararlanılmıştır.

$$
\mathrm{I}=\mathrm{A} \times \mathrm{Ep} \times \mathrm{Kcp} \times \mathrm{P}
$$

Eşitlikte; I: Parsele uygulanan sulama suyu (litre), A: Parsel alanı $\left(\mathrm{m}^{2}\right), \mathrm{E}_{\mathrm{p}}$ : Sulama aralığındaki birikimli Class A Pan buharlaşma miktarı (mm), Kcp: Farklı sulama suyu miktarını oluşturan katsayı, P: Örtü yüzdesini (\%) ifade etmektedir.

Sulama suyu kullanım etkinliği (IWUE) ve su kullanım etkinlik değerleri (WUE) belirlenerek sulama programları değerlendirilebilir (Howell ve ark. 1990). Bu amaçla aşağıdaki eşitliklerden yararlanılmıştır.

$$
\text { WUE }=E y / E T \quad I W U E=E y / I R
$$

Eşitlikte Ey Toplam şeker verimi (kg da-1), ET mevsimlik su tüketimini ( $\mathrm{mm})$, ve IR toplam sulama suyu miktarını $(\mathrm{mm})$ ifade etmektedir.

Deneme konularında, arıtılılmış şeker oranı (AŞO) Reinefeld ve ark, (1974) tarafından geliştirilen aşağıdaki eşitliklere göre hesaplanmıştır.

$$
\mathrm{AŞO}=\mathrm{P}-[0.343(\mathrm{Na}+\mathrm{K})+0.094 \mathrm{x} \alpha \mathrm{N}+0.29]
$$

Eşitlikte; $\mathrm{P}=$ Poları (\%); $\mathrm{K}=$ Potasyumu (mmol/100g kök); Na = Sodyumu $(\mathrm{mmol} / 100 \mathrm{~g}$ kök); $\alpha \mathrm{N}=$ Amino Azotu (mmol/100g kök) ifade etmektedir.

\section{Toprak Hazırlığı, Ekim ve Hasat}

Sonbaharda derin sürüm yapılarak kışa bırakılan deneme arazisi ilkbaharda kombikürüm ile ekime hazırlandıktan sonra sıra arası $45 \mathrm{~cm}$ olacak şekilde ekim yapılmıştır. Denemede tohumluk olarak Beta vulgaris cv. Coyote çeşidi kullanılmıştır. Toprak analiz

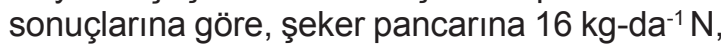

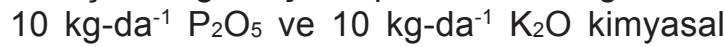
gübre verilmiştir. Parseller 6 metre uzunluğunda olup her parselde 8 bitki sırası yer almaktadır. Hasatta yanlardan ikişer bitki sırası ve parsel ucundan da birer metrelik alan kenar tesiri olarak alınmıştır..

\section{İstatistik Analiz Metotları}

Sonuçların istatistiksel analizleri bilgisayarda CoStat paket programı ile gerçekleştirilmiştir. Konular arasındaki ortalamalara ait değerlerin Duncan testi, MStatC paket programı ile yapılmıştır.

\section{Bulgular ve Tartışma}

\section{Sulama Suyu Uygulamaları ve Su Tüketimi}

Sulanmalara ilk yıl 26 Haziran tarihinde, ikinci yıl ise 21 Haziran tarihinde başlanılmıştır. Sulama sayıları konu gereği ilk yı 8 ile 22 arasında, ikinci yıl ise 9 ile 23 kez arasında değişmiştir. İlk sulamalarda tüm konulara eşit su verilerek 0-60 cm toprak profili tarla kapasitesine getirilmiş, daha sonraki sulamalarda ise konu gereği hesaplanan miktarlar uygulanmıştır. Sulama suyu miktarları, iki sulama arasında meydana gelen açık su yüzeyi buharlaşma miktarı ile bitkinin örtü yüzdesi dikkate alınarak hesaplanmıştır. Bu amaçla yapılan bitki taç genişliği ölçümlerinde 
üçüncü sulamada bitkilerin toprak yüzeyini tamamen kapladığı gözlenmiştir.

Konulara uygulanan sulama suyu miktarları pan katsayısına (Kpc) bağlı olarak değişiklik göstermiştir. Pan katsayısının artışına bağlı olarak gerek sulama suyu miktarı gerekse su tüketimleri artış göstermiştir (Çizelge 2 ve Çizelge 3). Kpc katsayısının 1.25 alındığı (a) konuları en fazla sulama suyu uygulanan konu olup bu konulara ilk yıl $668 \mathrm{~mm}$ ikinci yıl ise 665 $\mathrm{mm}$ su uygulanmıştır. Yine en yüksek su tüketimleri de (a) konularında gerçekleşmiştir.

Bilindiği gibi şeker pancarında \%16 polar (şeker miktarı) standart olarak kabul edilmektedir.

Devlet tarafından belirlenen şeker pancarı fiyatları \%16 polar değeri için geçerli olmaktadır. Üreticilerin yetiştirdikleri şeker pancarının polar değerinin bu standardın üzerinde veya altında çıkması alacağı şeker pancarı bedellerini de doğrudan etkilemektedir. Deneme konularından elde edilen şekerpancarlarının polar değerleri genel olarak standartlara eşit veya biraz altında çıkmışır (Çizelge 2 ve Çizelge 3). Denemenin ilk yılında konuların şeker oranları arasında önemli bir fark bulunmazken, ikinci yıl sulama düzeylerinin şeker oranına önemli düzeyde etkisi olmuştur $(P<0.01)$. Yapılan Duncan gruplamasında en az su verilen (d) konusu ilk grupta yer alırken Kpc katsayısı 1.00 olan (c) konusu ikinci grupta, diğer iki konu ise son grupta yer almışlardır. Deneme konularına uygulanan sulama suyu miktarı azaldıkça şeker pancarının şeker oranı artış göstermiştir. Daha önce yapılan çalışmalarda benzer bulgular elde edilmiştir. Topak ve ark. (2011) eksik sulamanın genellikle şekerpancarında şeker içeriğini artırdığını bildirmişlerdir. Bilgin (1992)'nin bildirdiğine göre aşırı sulama şekerpancarı verimini artırırken şeker oranını düşürmektedir.

Çizelge 2. 2008 deneme yılına dair deneme konularının su tüketimi ve bazı kalite parametre değerleri Table 2. Water consumptions and some quality parameters of subjects in 2008

\begin{tabular}{|c|c|c|c|c|c|c|c|c|}
\hline Konular & $\begin{array}{l}\text { Sulama } \\
\text { suyu, mm }\end{array}$ & $\begin{array}{l}\text { Su tüketimi, } \\
\text { l mm }\end{array}$ & Polar, \% & AŞO, \% & TŞV, kg/da & $\mathrm{K}$ & $\begin{array}{c}\mathrm{Na} \\
\mathrm{mmol} / 100 \mathrm{~g} \text { kök }\end{array}$ & $\alpha \mathrm{N}$ \\
\hline $\mathrm{Aa}$ & 668 & 767 & 15.62 & 13.91 & 1553 & 2.84 & 0.82 & 1.74 \\
\hline$A b$ & 538 & 648 & 15.52 & 14.12 & 1516 & 2.09 & 0.71 & 1.59 \\
\hline$A c$ & 409 & 535 & 15.78 & 14.02 & 1191 & 2.82 & 0.83 & 2.35 \\
\hline $\mathrm{Ad}$ & 279 & 411 & 16.15 & 14.37 & 986 & 2.70 & 1.02 & 2.24 \\
\hline $\mathrm{Ba}$ & 668 & 773 & 15.63 & 13.94 & 1673 & 2.77 & 0.81 & 1.81 \\
\hline $\mathrm{Bb}$ & 538 & 653 & 15.87 & 14.17 & 1529 & 2.54 & 1.03 & 1.92 \\
\hline $\mathrm{Bc}$ & 409 & 537 & 15.47 & 13.68 & 1163 & 2.80 & 0.89 & 2.44 \\
\hline $\mathrm{Bd}$ & 279 & 425 & 15.67 & 13.83 & 839 & 2.67 & 1.09 & 2.76 \\
\hline $\mathrm{Ca}$ & 668 & 764 & 15.35 & 13.65 & 1383 & 2.35 & 1.29 & 1.70 \\
\hline $\mathrm{Cb}$ & 538 & 653 & 15.67 & 13.90 & 1388 & 2.75 & 1.00 & 2.02 \\
\hline $\mathrm{Cc}$ & 409 & 532 & 15.45 & 13.80 & 1313 & 2.61 & 0.88 & 1.77 \\
\hline $\mathrm{Cd}$ & 279 & 407 & 16.12 & 14.32 & 963 & 2.73 & 0.97 & 2.51 \\
\hline
\end{tabular}

Çizelge 3. 2009 deneme yılına dair deneme konularının su tüketimi ve bazı kalite parametre değerleri Table 3. Water consumptions and some quality parameters of subjects in 2009

\begin{tabular}{ccccccccc}
\hline Konular & $\begin{array}{l}\text { Sulama } \\
\text { suyu, mm }\end{array}$ & $\begin{array}{l}\text { Su tüketimi, } \\
\mathrm{mm}\end{array}$ & Polar, \% & $\mathrm{AŞO}, \%$ & $\begin{array}{l}\mathrm{TŞV}, \\
\mathrm{kg} / \mathrm{da}\end{array}$ & $\mathrm{K}$ & $\begin{array}{c}\mathrm{Na} \\
\mathrm{mmol} / 100 \mathrm{~g} \text { kök }\end{array}$ & $\mathrm{aN}$ \\
\hline $\mathrm{Aa}$ & 665 & 821 & 16.23 & 14.55 & 1502 & 2.06 & 1.57 & 1.56 \\
$\mathrm{Ab}$ & 540 & 698 & 16.68 & 15.18 & 1542 & 2.23 & 0.90 & 1.46 \\
$\mathrm{Ac}$ & 415 & 605 & 16.53 & 14.66 & 1027 & 2.61 & 1.36 & 2.28 \\
$\mathrm{Ad}$ & 291 & 527 & 17.51 & 15.70 & 784 & 2.45 & 1.39 & 2.18 \\
$\mathrm{Ba}$ & 665 & 827 & 16.30 & 14.65 & 1476 & 2.16 & 1.47 & 1.26 \\
$\mathrm{Bb}$ & 540 & 721 & 16.66 & 15.01 & 1472 & 2.50 & 1.04 & 1.57 \\
$\mathrm{Bc}$ & 415 & 619 & 16.51 & 14.88 & 1186 & 2.36 & 1.06 & 1.85 \\
$\mathrm{Bd}$ & 291 & 524 & 17.24 & 15.54 & 893 & 2.28 & 1.31 & 1.83 \\
$\mathrm{Ca}$ & 665 & 816 & 16.10 & 14.44 & 1543 & 2.00 & 1.62 & 1.32 \\
$\mathrm{Cb}$ & 540 & 704 & 15.98 & 14.31 & 1382 & 2.08 & 1.58 & 1.40 \\
$\mathrm{Cc}$ & 415 & 614 & 16.70 & 15.09 & 1109 & 2.16 & 1.22 & 1.68 \\
$\mathrm{Cd}$ & 291 & 520 & 16.93 & 15.26 & 859 & 2.17 & 1.32 & 1.89 \\
\hline
\end{tabular}



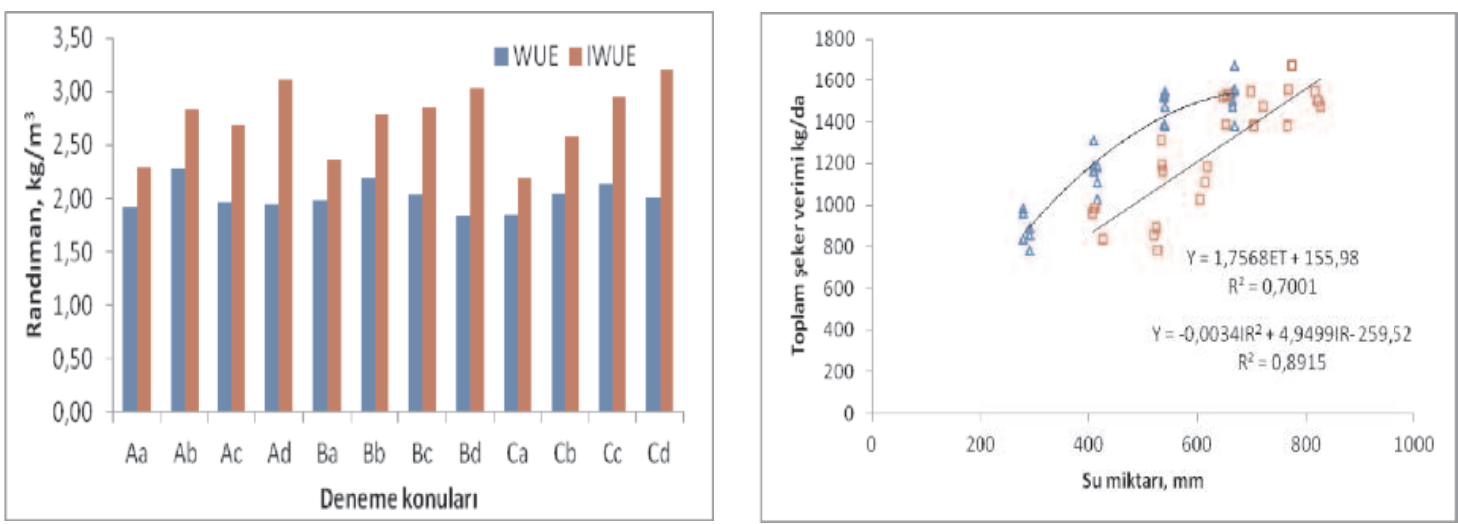

Şekil 1. Deneme konularına dair sulama randımanları ile su -TŞV ilişkileri

Figure 1. Irrigation efficiencies and water - sugar content relationships of experiment subjects

Uçan ve Gençoğlan (2004) farklı düzeylerde sulamanın şeker pancarı verimine ve kalitesine etkisi üzerine yaptıkları araştırmada uygulanan sulama suyu miktarı arttıkça şeker oranının düştüğünü belirlemişlerdir. Roberts ve ark. (1981) da şekerpancarında yapılan su kısıntısının şeker oranını artırdığını bildirmişledir.

Arıtılmış şeker oranları da (AŞO) polar sonuçları ile benzerlik göstermiştir. İlk deneme yılında uygulamaların AŞO üzerine önemli bir etkisi olmazken, ikinci yıl \%1 önem seviyesinde etkili olmuştur. Duncan gruplamasında konular az su uygulanan konudan çok sulanan konuya doğru yer almışlardır. Buna göre (d) konusu ilk grupta, en çok sulanan (a) konusu ise üçüncü ve son grupta yer almıştır. Bu sonuçla sulama ile AŞO arasında ters bir ilişkinin olduğunu göstermektedir.

Deneme konularının toplam şeker verimleri (TŞV) arasında her iki deneme yılında da önemli farklar ortaya çıkmıştır $(P<0.01)$. Sulama gün aralığının bu farklılığın oluşmasında etkisi önemsiz kalırken, sulama düzeyleri bu farklılığı ortaya çıkarmışlardır. Her iki deneme yılında da en fazla sulama suyunun uygulandığı (a) ve (b) konuları Duncan gruplamasında ilk grupta yer almışlardır. Şekil 1'de görüldüğü gibi uygulanan sulama suyu miktarı ile TŞV arasında ikinci dereceden önemli bir ilişki tespit edilmiştir $(P<0.01)$. Sulama suyu miktarının yanında bitki su tüketiminin de TŞV miktarında önemli etkisi mevcuttur $(P<0.01)$. Bitkinin su tüketimi arttıkça doğrusal olarak TŞV'de artmaktadır.

Deneme konularına ilişkin birim suya değerleri su kısıntısına bağlı olarak artmış ve genellikle daha az sulanan konulardan daha yüksek IWUE değerleri elde edilmiştir. Howell (2006) genellikle sulama düzeyi düştükçe IWUE değerinin artış eğiliminde ise belirgin bir eğilim oluşmamıştır. Bu konuda çalışan araştırmacılar su tüketimi ile
WUE arasında farklı görüşler ileri sürmüşlerdir. Howell (2003)'ın bildirdiğine göre WUE genellikle sulama arttıkça artış eğilimindedir.

Ancak, Fabeiro et al. (2003) WUE nin maksimum gerçekleşmediğini, evapotranspirasyonda evapotranspirasyondan çok evapotranspirasyona doğru arttığını ifade etmişlerdir. Bu çalışmada en yüksek WUE değerleri Kpc katsayısının 1.00 olarak alındığı (b) konuları ile 0.75 olarak alındığı (c) konularında gerçekleşmiştir.

Bu araştırmadan elde edilen WUE değerleri yapılan birçok çalışmanın sonuçları ile benzerlik göstermiştir. Cassel Sharmasarkar et al. (2001) WUE nin 9.60 ile $10.60 \mathrm{~kg} \mathrm{~m}^{-3}$ arasında değiştiğini, Topak ve ark. (2011) WUE nin 7.46 ile $8.32 \mathrm{~kg} \mathrm{~m}^{-3}$ arasında değiştiğini bildirmişlerdir. Şeker pancarı için belirlenmiş IWUE değerleri ise büyük farklılıklar göstermiştir. Hassanli ve ark (2010) IWUE sulama metoduna bağlı olarak 3.6 ile 9.0 arasında değiştiğini bildirirken, Topak ve ark. (2011) 7.91-11.50 arasında değiştiğini rapor etmekte, Uçan ve Gençoğlan (2004) ise 2.61 ile 4.68 arasında farklı değerler aldığını ifade etmişlerdir.

\section{Sonuçlar}

Bu sonuçlara göre damla sulama sistemi ile sulanan şekerpancarında laterallar $90 \mathrm{~cm}$ aralıklarla dizayn edilmelidir. Sulamalarda sulama suyu ile ilgili herhangi bir kısıt yok ise açık su yüzeyi buharlaşmasının 1.25 katı kadar su uygulanmalıdır. Su kısıntısı durumunda bu oran 1.00 alınmalıdır. Şeker pancarının damla sulama ile sulanmasında, gerek örtü yüzdesi değerlerinin kullanılmasıyla, gerekse yüksek sulama randımanı sağlanmasıyla yüzey sulamaya göre daha az sulama suyuna gereksinim duyulacağı dikkate alınmalıdır. 


\section{Kaynaklar}

Bilgin Y, 1992. Şeker Pancarı Verim ve Kalitesini Etkileyen Bazı Faktörler. Türkiye Şeker Fabrikaları A.Ş. Şeker Enstitüsü seminer notları. Ankara, s: 1-18

Cassel Sharmasarkar FC, Sharmasarkar S, Miller SD, Vance GF, Zhang R, 2001. Assessment of Drip and Flood İrrigation on Water and Fertilizer Use Efficiencies for Sugar Beets. Agric Water Manage 46 : 241-251

Clarke R, 1993. Water: The International Crisis. Earthscan Publications Ltd., London 193 p.

Çetin Ö, Bilgel L, 2002. Effects of Different İrrigation Methods on Shedding and Yield of Cotton. Agric Water Manage 54 : 1-15

Ertek A. ve Kanber R., 1999. Damla sisteminde farklı sulama programlarının pamuk bitkisinin değişik toprak katmanlarındaki su tüketimine ve kök gelişimine etkilerinin belirlenmesi. Agri. Foresty, $34: 283-291$

Fabeiro C., Santa Olalla M., Lopez R. ve Dominguez A., 2003. Production and quality of sugar beet (Beta vulgaris L.) cultivated under controlled deficit irrigation condition in semi-arid- climate. Agric Water Manage 62 : 215-227.

Hassanli A.M., Ahmadirad S. ve Beecham S., 2010. Evaluation of the influence of irrigation methods and water quality on sugar beet yield and water use efficiency, Agricultural Water Management $97: 357-362$

Howell T.A., 2003. Irrigation Efficiency. In: Stewart, B.A., Howell, T.A. (Eds.), Encyclopedia of Water Science. Dekker, pp. 467-472.

Howell T.A., Cuenca R.H. ve Solomon K.H., 1990. Crop Yield Response. In: Hoffman, et al. (Eds.), Management of Farm Irrigation Systems. ASAE, pp. 311-312

Howell T.A., 2006. Challenges in İncreasing Water Use Efficiency in Irrigated Agriculture. In: The Proceedings of International Symposium on Water and Land Management for Sustainable Irrigated Agriculture, 4-8 April 2006, Adana.

Korukçu A. ve Büyükcangaz H., 2003. Su ve Sulama Yönetimine Bütünsel Yaklaşım. 2. Ulusal Su Kongresi, 16-19 Ekim, Kuşadası, İzmir, 19-32

Kruse E.G., Bucks D.A. ve Von Bernuth R.D., 1990. Comparison of irrigation systems. Agron. Monogr. 30, 475-508
Özbahçe A. ve Tarı A.F., 2010. Effects of different emitter space and water stress on yield and quality of processing tomato under semi-arid climate conditions. Agric Water Manage 97 : 1405-1410

Reinefeld E., Emmerich A., Baumgarten G., Winner C., Beiß U., 1974. Zur voraussage des melassezuckers aus rübenanalysen. Zucker, 27 : 2-15

Roberts S., Weaver W.H. ve Richards A.W., 1981. Sugar beet response to incremental application of nitrogen with high frequency sprinkler Irrigation. Soil Sci Soc Am J, 45 : 448-449

Scott R.K. ve Jaggard K.W., 1993. Crop Physiology and Agronomy. In: The sugar Beet Crop: Science into Practice. (Editörler: Cooke DA, Scott RK). Chapman and Hall, London.179-233

Sakellariou-Makrantonaki I., Kalfountzos D. and Vyrlas P., 2002. Water saving and yield increase of sugar beet with subsurface drip irrigation. Global Nest Int J 4(2-3):85-91

Tarı A.F. ve Yazar A., 2010. Konya-llgın ovasındaki bireysel yağmurlama sulama sistemlerinin bazı performans parametreleri. Harran Üniversitesi Ziraat Fakültesi Dergisi 14 (1) : 45-56

Tekinel O., Kanber R., Çetin M., 2000. Su Kaynaklarının Geliştirme ve Kullanımı. Türkiye Ziraat Mühendisliği V. Teknik Kongresi, Ankara, 231259

Tognetti R., Palladino M., Minnocci A., Defline S., Alvino A., 2003. The Response of sugar beet to drip and low-pressure sprinkler ırrigation in southern Italy. Agric Water Manage 60 : 135-155

Topak R., Süheri S., Acar B., 2008. Climatic, Agricultural Drought, Irrigation and Environment Relationships in Konya Basin. In: Proceedings of the Conference on Groundwater and Drought in Konya Closed Basin, September 11-12. Konya, Turkey, pp 67-76

Topak R., Süheri S. ve Acar B., 2011. Effect of different drip irrigation regimes on sugar beet (Beta vulgaris L.) yield, quality and water use efficiency in Middle Anatolian, Turkey. Irrig Sci $29: 79-89$

Uçan K. ve Gençoğlan C., 2004. The Effect of water deficit on yield and yield components of sugar beet. Turk J Agric For 28 : 163-172 